\title{
O Uso de Informações Patentárias para a Valorização DE RESíduOS INDUSTRIAIS: O CASO DO LODO DE TRATAMENTO DE ESGOTO DOMÉSTICO
}

\author{
Information on Patents in the Area of Industrial Residues Recovery:
} the case of sludge from domestic wastewater treatment

\section{Delmar Hirata}

Químico da Companhia de Saneamento Básico do Estado de São Paulo - (SABESP.) Universidade Nove de Julho. Vila Itaberaba. São Paulo, SP, Brasil.E-mail: delmarhirata@hotmail.com

\section{Cláudia Terezinha Kniess}

Professora do Programa de Pós-graduação em Cidades Inteligentes e Sustentáveis e do Programa de Mestrado Profissional em Administração - Gestão Ambiental e Sustentabilidade. Universidade Nove de Julho. São Paulo, SP, Brasil. E-mail: ctkniess@uninove.br

\section{Tatiana Tucunduva Philippi Cortese}

Professora do Programa de Pós-graduação em Cidades Inteligentes e Sustentáveis e do Pro.Universidade Nove de Julho rama de Mestrado Profissional em Administração - Gestão Ambiental e Sustentabilidade. São Paulo, SP, Brasil. E-mail: taticortese@uninove.br

\section{Luc Quoniam}

Professor do Programa de Pós-graduação em Administração. Universidade Nove de Julho. São Paulo, SP. Brasil. E-mail: mail@quoniam.info

\section{Resumo}

A disposição do lodo de esgoto é um problema em muitas comunidades brasileiras. $\mathrm{O}$ tratamento e reciclagem podem ser considerados um exemplo de inovação sustentável, em prol da obtenção de novos materiais. $\mathrm{O}$ processo de produção de conhecimento constitui o tema central em estudos sobre gestão da inovação tecnológica, entretanto são incipientes os estudos que tratam da comercialização desses conhecimentos, sobre o patenteamento e o licenciamento das tecnologias produzidas sob a ótica administrativa. Diante desse cenário, este estudo teve como objetivo fazer um levantamento das tecnologias utilizadas para a reciclagem do lodo de tratamento de esgoto na obtenção de novos produtos por meio das informações disponíveis nos bancos de dados internacionais sobre patenteamento. Nesse sentido, foi elaborado um estudo empírico, exploratório, com abordagem qualitativa, baseado em um levantamento bibliográfico e na avaliação das informações sobre os pedidos e resultados de patentes existentes em bancos de dados internacionais.

Palavras-chave: Inovação Sustentável. Reciclagem. Lodo de Esgoto. Patentes.

\section{Abstract}

The disposal of sewage sludge is a problem in many Brazilian communities. Their treatment and recycling is an example of sustainable innovation for obtaining new materials. The production process of this knowledge is a central theme in studies of technological innovation management, however are incipient studies that deal with the marketing of such knowledge on patenting and licensing of technologies produced under the administrative perspective. In this scenario, this study aimed to raise the technology used for recycling sludge, in order to obtain ceramic products. In this sense, was drawn up an empirical and exploratory study with a qualitative approach, based on a literature survey and assessment of information on the applications and results of existing patents in international databases.

Keywords: Sustainable Innovation. Recycling. Sewage Sludge. Patents. 


\section{INTRODUÇÃO}

Com base na abordagem schumpeteriana, Calazans (1992) afirma que o processo de desenvolvimento de uma nação encontra-se enraizado nas condições locais e na capacidade dos agentes de se articular, interagir, cooperar e aprender com o objetivo de criar algo novo, isto é desenvolver a inovação. Nesse contexto, a inovação é definida por Tidd, Bessant e Pavitt (2008) como o ato ou efeito de inovar, ou seja, tornar algo novo, renovar ou introduzir uma novidade, isto é, a tentativa de oferecer algum produto novo ou modificado, um bem ou serviço à sociedade, resultantes de um processo de aprendizado (organizational and individual learning) ou do caráter path-depedence e das rotinas que geram competências e capacitações, que podem estar condicionadas pela interação de agentes econômicos, produtivos e de desenvolvimento de tecnologias. Uma inovação tecnológica é definida pela introdução no mercado de um produto, ou processo, produtivo tecnologicamente novo ou substancialmente aprimorado (OCDE, 2005).

Quanto à importância da inovação, Freeman e Soete (2008) discutem que as inovações são condições essenciais para o progresso econômico e um elemento crítico na competitividade entre as empresas das nações. Segundo Tidd, Bessant e Pavitt (2008), o processo de inovação é um processo-chave do negócio da empresa, associado com a renovação e a evolução do negócio, renovando o que a empresa oferece e como ela cria e entrega aquela oferta. Portanto, a inovação pode ser considerada uma atividade essencial ligada à sobrevivência e ao crescimento da organização.

Para atender às dimensões da sustentabilidade, as inovações devem gerar resultados econômicos, sociais e ambientais positivos, ao mesmo tempo. Cabe salientar a dificuldade de conciliar esses interesses sem perder competitividade, considerando-se as incertezas que as inovações trazem, essencialmente quando muito radicais ou com elevado grau de novidade (BARBIERI et al., 2010)

Como exemplo de inovação sustentável pode-se citar o reaproveitamento do lodo de tratamento de esgoto doméstico na obtenção de novos materiais. A disposição do lodo de esgoto é um problema comum em muitas comunidades no Brasil. Os principais agentes poluidores dos recursos hídricos nas áreas urbanas são os esgotos, que muitas vezes são lançados diretamente nos corpos de água. A falta de condições adequadas de saneamento pode contribuir para a proliferação de inúmeras doenças parasitárias e infecciosas, além da degradação dos corpos d'água (COSTA; COSTA, 2011).

A disposição final adequada deste resíduo é uma etapa problemática no processo operacional de uma Estação de Tratamento de Esgoto (ETE), pois seu planejamento tem sido negligenciado e apresenta um custo que pode alcançar $60 \%$ do orçamento operacional de um sistema de tratamento. A gestão dos resíduos pode significar um mercado com boas perspectivas potenciais nas áreas de projeto, planejamento e gestão de serviços, equipamentos e insumos (ANDREOLI; PEGORINI, 1998; MIKI; ANDRIGUETI; ALEM SOBRINHO, 2001).

Segundo Barbieri et al. (2010a), o processo de produção de conhecimento e sua implementação por parte da organização constitui o tema central da literatura sobre gestão da inovação tecnológica. No entanto, poucos são os trabalhos que tratam da comercialização desses conhecimentos, assunto relacionado com o processo de transferência de tecnologia entre diferentes organizações. Também são poucos os estudos sobre patenteamento e licenciamento das tecnologias produzidas sob a ótica administrativa disponíveis na literatura.

Para garantir a apropriação dos resultados obtidos a partir do processo constituído de inovações tecnológicas das empresas que investiram em Pesquisa $e$ Desenvolvimento, a sociedade concede, por meio da patente, a essas organizações, um método de proteção legal temporária. A patente permite a exploração da inovação em troca da informação detalhada sobre parte substancial do conteúdo técnico contido naquela matéria protegida por lei. O processo de transferência de tecnologia engloba o licenciamento de patentes e está diretamente relacionado à comercialização $e$ à atribuição de lucros sobre inovações (GARNICA; TORKOMIAN, 2009).

Os dados de patentes podem mostrar alterações na estrutura e no desenvolvimento de atividades criativas de um país nas tecnologias, na indústria $e$ nas empresas. As patentes também podem indicar as mudanças de dependência de determinadas tecnologias, além de sua disseminação e penetração científica, 
técnica e, em última instância, mercadológica (ORGANISATION FOR ECONOMIC CO-OPERATION AND DEVELOPMENT, 2002).

Dentro desse contexto, este trabalho busca responder à seguinte questão de pesquisa: Como se caracterizam as tecnologias que envolvem a inovação sustentável relacionada a reciclagem do lodo de tratamento de esgoto para a obtenção de novos produtos? Para responder à questão de pesquisa, este trabalho tem como objetivo principal fazer um levantamento das tecnologias utilizadas para a reciclagem do lodo de tratamento de esgoto na obtenção de novos produtos por meio das informações disponíveis nos bancos de dados internacionais sobre patenteamento.

\section{ReVISÃo TEÓRICA}

A seguir serão descritos os principais conceitos relacionados aos principais constructos do trabalho: inovação sustentável, lodo de tratamento de esgoto $e$ propriedade industrial.

\subsection{Inovação Sustentável}

As inúmeras mudanças no cenário global têm incentivado as organizações a inovar, gerenciar mudanças e promover o surgimento de novos produtos e serviços de forma sustentável. Esse contexto traz novas barreiras para as organizações, com o aumento da complexidade dos desafios e da velocidade requerida para manutenção e desenvolvimento dos negócios. Dessa forma, é necessário que as organizações aprimorem o processo de criação e o gerenciamento de alternativas inovadoras de produtos, processos e recursos que sejam cada vez mais eficientes e eficazes.

Nesse contexto encontra-se a inovação sustentável. O termo sustentável tem origem no conceito de desenvolvimento sustentável. Conforme o documento "Nosso Futuro Comum" (Relatório de Brundtland) redigido em 1991, desenvolvido pela Comissão Mundial sobre Meio Ambiente e Desenvolvimento, o desenvolvimento sustentável é aquele que atende às necessidades presentes sem comprometer a capacidade das gerações, ou seja, trata-se do desenvolvimento que atende às necessidades do presente, sem comprometer as necessidades das gerações futuras (WECD, 1987).
Inovação é algo novo que agregue valor social ou riqueza e que pode ser um produto ou algo de inovador em tecnologias, processos operacionais, práticas mercadológicas, ou outras pequenas mudanças ou adaptações, mas que gere ganhos econômicos através da prática (TIDD; BESSANT; PAVITT, 2008).

As Inovações Tecnológicas em Produtos e Processos (TPP) compreendem as implantações de produtos e processos tecnologicamente novos e substanciais melhorias tecnológicas em produtos e processos. Uma inovação TPP é considerada implantada se tiver sido introduzida no mercado (inovação de produto) ou usada no processo de produção (inovação de processo). Esta envolve uma série de atividades científicas, tecnológicas, organizacionais, financeiras e comerciais (OCDE, 2005).

Barbieri et al. (2010) definem inovação sustentável como a introdução (produção, assimilação ou exploração) de produtos, processos produtivos, métodos de gestão ou negócios, que sejam novos ou significativamente melhorados para a organização em questão, trazendo benefícios econômicos, sociais e ambientais, quando comparados com alternativas pertinentes, não apenas reduzindo impactos negativos, mas avançando em benefícios líquidos.

Casagrande Jr. (2011, p. 15) define como inovação tecnológica sustentável a "[...] interação entre inovação e a tecnologia ajustada a nossa realidade e associada aos princípios do desenvolvimento sustentável". O autor pontua que inovação tecnológica sustentável pode acontecer por meio de estratégias de transição, sob uma plataforma de práticas interdisciplinares e esforços interinstitucionais que englobam órgãos públicos de educação, sociedade civil e iniciativa privada.

Exemplos significativos de práticas de inovação sustentável podem ser pontuados: mudanças em design de produto, utilização de novos materiais de baixo impacto ambiental, aproveitamento de materiais reciclados, processos com emissão zero, uso de substâncias de base natural e capacitação de trabalhadores conscientes do processo (CASAGRANDE JR, 2011). O reaproveitamento do lodo de tratamento de esgoto doméstico como matéria-prima alternativa na obtenção nos produtos, foco deste trabalho, pode ser considerado um exemplo de inovação sustentável. 


\subsection{Lodo de Tratamento de Esgoto}

Com o crescimento populacional, a quantidade de esgotos lançados nos rios tomou tamanha dimensão que a capacidade de autodepuração desses rios passou a ser insuficiente para que fosse possivel a captação de água com qualidade para o tratamento e abastecimento público. Assim, sistemas de tratamento que reproduzem os fenômenos naturais de degradação da matéria orgânica presente no esgoto, de forma mais controlada e rápida, foram introduzidos após os sistemas de esgotamento sanitário, entre as etapas de afastamento e lançamento nos corpos d'água e são chamados estações de tratamento de esgotos (ETE).

As estações de tratamento de esgotos visam à remoção de matéria orgânica, sendo realizada por processos físicos, químicos e biológicos, nos quais as bactérias são os principais microrganismos responsáveis pela degradação ou a estabilização da matéria orgânica. O esgoto sanitário é composto de mais de 99,9\% de água, sendo o restante (inferior a $0,1 \%$ ) composto de matéria orgânica em suspensão e dissolvido (em estado coloidal e em solução), orgânico e inorgânico, bem como micro-organismos (MIKI et al., 2001).

A necessidade de tratar do esgoto urbano é fator importante para se manter a qualidade dos recursos hídricos e a saúde humana. O processo do tratamento do esgoto ocorre nas ETEs. No entanto, com a instalação das ETEs surge um novo problema ambiental: a disposição do lodo de esgoto, resíduo produzido durante o processo de tratamento das águas residuais.

Segundo Santos e Tsutiya (1997), lodos são sólidos acumulados, separados dos líquidos durante os processos de tratamento de água para abastecimento ou de esgoto, ou depositados no fundo dos rios ou outros corpos d'água. A NBR 10004 (ASSOCIAÇÃO BRASILEIRA DE NORMAS TÉCNICAS, 2004) classifica os lodos provenientes de estações de tratamento de esgoto como resíduos sólidos, de modo que tais resíduos devem ser devidamente tratados e dispostos sem provocar danos ao meio ambiente.

Em novembro de 2003, o Conselho Nacional do Meio Ambiente (CONAMA) recebeu uma solicitação realizada pela EMBRAPA para elaborar uma Resolução regulamentando o uso agrícola de lodo de esgoto. O grupo de trabalho, formado por representantes de diferentes setores envolvidos com o tema, como com- panhias de saneamento, órgãos ambientais, instituições de pesquisa, entre outros, finalizou seus trabalhos em maio de 2005 e publicou a Resolução n. 375/2006. Referida Resolução estabelece critérios e procedimentos para o uso agrícola de lodos de esgoto gerados em estações de tratamento de esgoto sanitário e seus produtos derivados.

Segundo Metcalf e Eddy (1995), entre os produtos resultantes do tratamento de esgoto, o lodo tem o maior volume e requer um difícil tratamento e disposição final. Sendo assim, o lodo constitui um problema complexo que as empresas de saneamento enfrentam. Os problemas derivados do manejo do lodo são complexos, como estes: (a) o lodo é formado, principalmente, pelas substâncias responsáveis pelo caráter desagradável das águas residuais não tratadas; (b) a fração do lodo a ser disposta, gerada no tratamento biológico do esgoto, é composta principalmente pela matéria orgânica presente; (c) somente uma pequena parte do lodo é composta por matéria sólida.

A escolha de alternativas de disposição final do lodo é fruto da situação local de tecnologia e recursos disponíveis. No Brasil, a disposição final do lodo geralmente é o aterro sanitário. Segundo a EMBRAPA, além do alto custo, que pode chegar a $50 \%$ do custo operacional de uma ETE, a disposição de um resíduo com elevada carga orgânica no aterro, torna mais grave o problema com o manejo do lixo urbano (AMBIENTE BRASIL, 2006). Em países da Europa e da América do Norte, o lodo geralmente é depositado em aterros sanitários, utilizado em áreas agrícolas ou incinerado, dependendo das características do resíduo.

$\mathrm{Na}$ maioria dos países há normas que regulamentam o destino do lodo, garantindo uma disposição segura. A adição ao solo parece ser a melhor opção sob o ponto de vista econômico e ambiental, uma vez que apresenta o menor custo e promove a reciclagem de matéria orgânica e de nutrientes.

O uso agrícola de biossólidos ainda não foi amplamente difundido no Brasil, entretanto já faz parte de programas nacionais de controle de impactos ambientais, por exemplo, na área temática intitulada "Agricultura sustentável" da Agenda 21 Brasileira. Discute-se amplamente a necessidade da recuperação de solos erodidos e empobrecidos e uma das práticas incentivadas para conservação e recuperação dos solos é o uso de lodo de esgotos domésticos em solos agríco- 
las, mediante a garantia de que não ocorram impactos ambientais negativos (AMBIENTE BRASIL, 2006).

A eficácia do uso agrícola de biossólidos tem sido tema de pesquisas no Brasil. Com a possível presença de poluentes como metais pesados, patógenos e compostos orgânicos persistentes, a sua utilização pode trazer impactos ambientais negativos. $\mathrm{O}$ nitrato também representa um problema devido à falta de sincronismo entre a absorção pelas plantas e sua mineralização, podendo resultar em risco de contaminação do lençol freático. Uma vez adicionados ao solo, alguns dos poluentes podem entrar na cadeia alimentar ou acumular-se no próprio solo, no ar, nas águas superficiais, nos sedimentos e nas águas subterrâneas. Portanto, é necessária uma rigorosa regulamentação para a adição do resíduo ao solo, bem como estudos que determinem riscos ambientais a curto e longo prazos (EMBRAPA 2006).

A Lei Federal n. 12.305/2010 instituiu a Política Nacional de Resíduos Sólidos, que estabelece diretrizes relativas à gestão integrada $e$ ao gerenciamento de resíduos sólidos e dispõe sobre as responsabilidades dos geradores de resíduos e do poder público. Foi regulamentada pelo Decreto n. 7.404, de 23 de dezembro de 2010, que também criou o Comitê Interministerial da Política Nacional de Resíduos Sólidos e o Comitê Orientador para a Implantação dos Sistemas de Logística Reversa. Entre os principais objetivos dessa lei, é possível notar a proteção da saúde pública e da qualidade ambiental estimulando padrões sustentáveis de produção e consumo de bens e serviços com desenvolvimento e aprimoramento de tecnologias limpas; a não geração, redução, reutilização, reciclagem $e$ tratamento dos resíduos sólidos, bem como disposição final ambientalmente adequada dos rejeitos; e a gestão integrada dos resíduos sólidos que busca compartilhar a responsabilidade pelo ciclo de vida dos produtos, envolvendo todos da cadeia de comercialização, como fabricantes, distribuidores, consumidores e órgãos públicos (BRASIL, 2010).

Considerando que um dos objetivos principais dessa Lei é o reaproveitamento dos resíduos sólidos, um plano microrregional que integre as ações de municípios limítrofes pode diminuir custos para o reaproveitamento adequado do lodo de esgoto. Principalmente porque o artigo 36, alínea $\mathrm{V}$, deixa claro que o titular dos serviços públicos de limpeza urbana e manejo de resíduos sólidos será responsável por "[...] implantar sistema de compostagem para resíduos sólidos orgânicos e articular com os agentes econômicos e sociais formas de utilização do composto produzido".

A utilização de lodos de estações de tratamento de esgotos como matéria-prima na indústria cerâmica é uma prática que vem sendo adotada em vários países (Alemanha, Espanha, Japão entre outros) e apresenta uma série de vantagens em relação a outros tipos de uso, pois as operações inerentes à indústria cerâmica (fornos operando em altas temperaturas) fazem com que os riscos sanitários sejam reduzidos ao máximo (ARAÚJO et al., 2005).

Diante de tal problemática envolvendo o tratamento, disposição e reciclagem do lodo de esgoto, a busca de informações nas bases de patentes podem ser utilizadas como fonte de identificação de alternativas tecnológicas que visam à minimização ou até a solução dos problemas que envolvem o caso em questão.

\subsection{Propriedade Industrial}

A Propriedade Intelectual engloba o campo de Propriedade Industrial, os Direitos Autorais e outros Direitos sobre bens materiais de vários gêneros, tais como os Direitos Conexos e as Proteções Sui Generis (INPI, 2015). A propriedade industrial é o conjunto de direitos que compreende as patentes de invenção e de modelo de utilidade, os registros de desenho industrial, as marcas e as indicações geográficas, bem como a repressão da concorrência desleal.

O objetivo da propriedade industrial é garantir o direito de exploração comercial da propriedade intelectual aos titulares por período determinado de tempo, restringindo o uso não autorizado por terceiros. Do lado da empresa, a patente consiste em uma reserva de mercado garantida pela patente durante sua vigência, sobre uma novidade sob o ponto de vista técnico-científico. Para a universidade, o patenteamento e a exploração comercial de determinada tecnologia garante recursos à universidade para o financiamento de novas pesquisas, além da divulgação e da aproximação da pesquisa acadêmica com as necessidades de mercado (FUJINO; STAL, 2004).

Os direitos de Propriedade Industrial podem mensurar a produção da atividade inovadora de um país, a partir das invenções. Apesar da invenção em si não ser 
considerada inovação, existe estreita relação entre patentes e saída inovadora. Sendo assim, publicações científicas que estudam os fatores e a influência da inovação utilizam tal indicador (ORGANISATION FOR ECONOMIC CO-OPERATION AND DEVELOPMENT, 2002).

Patente é um título de propriedade temporária sobre uma invenção, ou modelo de utilidade, outorgados pelo Estado aos inventores ou autores ou outras pessoas físicas ou jurídicas detentoras de direitos sobre a criação. Em contrapartida, o inventor se obriga a revelar detalhadamente todo o conteúdo técnico da matéria protegida pela patente (PULHMAN; MOREIRA, 2004). A patente pode ser considerada uma ferramenta para a disseminação da informação, podendo ser utilizada como: (a) fonte de dados para os indicadores do grau de desenvolvimento tecnológico e econômico; (b) fonte de acompanhamento da evolução tecnológica; (c) fonte de identificação detentores de tecnologias concorrentes, tendências tecnológicas e mercados potenciais. A informação sobre a patente está disponível após a publicação. A propriedade é limitada temporalmente; findo o prazo de vigência, o conhecimento protegido na patente poderá ser utilizado livremente.

As patentes podem ser divididas em Patentes de Invenção ou Patentes de Modelo de Utilidade. As Patentes de Invenção (PI) têm como requisitos a novidade, a aplicação industrial, a atividade inventiva e a suficiência descritiva, seu prazo de vigência é de 20 anos a partir da data do depósito. As patentes de Modelo de Utilidade (MU) são objetos de uso prático, ou parte desses, suscetível de aplicação industrial, que apresente nova forma ou disposição, envolvendo o ato inventivo, que resulte em melhoria funcional no seu uso ou fabricação. O prazo de vigência das patentes de modelo de utilidade é de 15 anos (INSTITUO NACIONAL DE PROPRIEDADE INDUSTRIAL, 2015).

As patentes podem ser consideradas fontes importantes de informações uma vez que os resultados tecnológicos apresentados para realização do pedido de patenteamento raramente são replicados em outras publicações (BARROSO et al., 2004). Pulhman e Moreira (2004) colocam que as patentes podem ser utilizadas como fonte de informação para diversas finalidades, dentre as quais se destacam: (a) identificação de alternativas tecnológicas; (b) identificação de desenvolvimentos tecnológicos já realizados; (c) avaliação de mercados futuros, uma vez que o patenteamento costuma preceder a comercialização em alguns anos; (d) avaliação de tecnologias emergentes, de modo a caracterizar as tendências do desenvolvimento tecnológico de determinada área do conhecimento; (e) avaliação das atividades de Pesquisa e Desenvolvimento e detecção de mudanças estratégicas de instituições e empresas.

Os escritórios responsáveis por registrar pedidos de patentes são de livre acesso do público pela internet e mantém bancos de dados com descrições completas das invenções apresentadas para depósito. As patentes depositadas, aprovadas ou não, bem como a descrição das invenções em termos funcionais e de aplicação permanecem disponíveis e visíveis para o público em geral formando uma grande biblioteca tecnológica (DOU, 2010). Segundo Quoniam, Kniess e Mazzieri (2014), a patente é vista como uma forma de expressar ao mercado, a investigação puramente técnica e tecnológica. Ressalta-se que a patente pode conduzir a pesquisa, além da estrita investigação técnica.

Em comparação com outras fontes de informação tecnológica, a documentação de patentes apresenta vantagens consideráveis, dentre as quais: (a) divulgar informação mais rapidamente do que outras fontes porque na maioria dos países os documentos são publicados antes de sua concessão e, assim, a tecnologia mais recente chega ao conhecimento do público mais rapidamente; (b) possuir uma estrutura uniforme relativa ao "layout" do documento e aos dados bibliográficos, que são identificados por códigos utilizados por todos os países por meio da Classificação Internacional de Patentes (IPC), o que permite uma recuperação fácil da tecnologia desejada, bem como fornece uma base para determinação de dados estatísticos de certos parâmetros tecnológicos (WIPO, 2015).

\section{Metodologia}

O procedimento metodológico caracteriza-se como sendo o ponto central de qualquer investigação científica (MARTINS; TEÓPHILO, 2009). A definição de uma estratégia adequada de pesquisa possibilita o alcance de conclusões baseadas em evidências.

A pesquisa empírica desenvolvida neste trabalho pode ser classificada quanto aos objetivos como exploratória. Gil (1999) destaca que a pesquisa exploratória 
é desenvolvida no sentido de proporcionar uma visão global acerca de determinado fato.

No campo das ciências sociais aplicadas há fenômenos de elevada complexidade e de difícil quantificação, onde abordagens qualitativas são adequadas, tanto no que diz respeito ao tratamento contextual do fenômeno, quanto no que tange à sua operacionalização. O tratamento de eventos complexos pressupõe um maior nível de detalhamento das relações dentro das organizações, entre os indivíduos e as organizações, bem como dos relacionamentos que estabelecem com o meio ambiente em que estão inseridos (MARTINS; TEÓPHILO, 2009). A pesquisa qualitativa é aquela que se distingue pela não utilização de métodos ou ferramentas estatísticas para a análise de dados, não sendo, contudo, uma mera "especulação subjetiva", uma vez que esse tipo de análise tem por base sólidos conhecimentos teórico-empíricos que fundamentam sua cientificidade.

No caso do trabalho em questão, busca-se avaliar as informações sobre os pedidos e resultados de patenteamento envolvendo a valorização do lodo de tratamento de esgoto doméstico como matéria-prima alternativa na obtenção nos produtos, especificamente produtos cerâmicos. Estas informações estão disponíveis nos diversos bancos de dados dos órgãos governamentais competentes, principalmente o Instituto Nacional de Propriedade Industrial (INSTITUO NACIONAL DE PROPRIEDADE INDUTRIAL, 2015), o European Patente Office (EPO, 2015) e o World Intellectual Property Organization (WIPO, 2015).

A coleta de dados fez uso de dados secundários como visita a sítios na internet, materiais de divulgação e publicações oficiais. Nesse contexto, foi realizado um levantamento na literatura da área sobre as alternativas de disposição e reciclagem do lodo de tratamento de esgoto. Na sequência foram consultadas as informações relacionadas ao caso em questão disponíveis no European Patente Office (EPO, 2013), especificamente a ferramenta Patent2Net (http://patent2net.vlab4u.info/), software livre desenvolvido em linguagem phyton, multiplataforma (Linux, Windows) roda em Command Line interface (CLI) (CARVALHO; STOROPOLI; QUONIAM, 2014).

Para execução da pesquisa utilizou-se metodologia empregada por outros autores como: De Melo Maricato et al. (2010), Serafini et al. (2012), Melo e Czarnobay (2014) e Uchôa, Silva e Silva (2014).
A pesquisa dos pedidos de patentes referentes ao tema foi realizada nos meses de junho e julho de 2015, sendo utilizada uma estratégia de busca que combinou os campos de título, resumo e código de patente.

Utilizou-se a base de dados da EPO - European Patent Office, por meio da ferramenta Espacenet, disponível em < http://worldwide.espacenet.com/ > . Para extração $e$ análise dos dados foi utilizada a ferramenta Patent2Net.

Na primeira etapa da pesquisa foram utilizadas as seguintes palavras-chave: "sewage sludge", recy* e utiliz*. O objetivo dessa etapa foi de levantar as tecnologias empregadas na reciclagem de lodo de esgoto. A segunda etapa da pesquisa foi analisar as patentes com objetivo de desenvolver novos materiais, portanto foi adicionado ao critério de pesquisa o código International Patent Classification (IPC) C04B - (cimento; concreto; pedra artificial; cerâmica; refratários). Os resultados foram descritos pelas frequências dos códigos de classificação de patentes, ano, países, inventores e requisitantes de depósitos.

A partir das informações obtidas realizou-se um levantamento relacionado aos seguintes parâmetros:

a) Países com mais pedidos de patentes relacionados à área em questão.

b) Distribuição anual dos pedidos de patentes.

c) International Patent Classification predominantes para a pesquisa realizada.

d) Tecnologias predominantes sobre a reciclagem do lodo de esgoto.

\section{Resultados e Discussão}

Nesta seção serão apresentados e discutidos os resultados obtidos a partir da busca na literatura de alternativas de disposição e reciclagem do lodo de esgoto e informações da base de dados sobre patenteamento.

\subsection{Alternativas de Disposição e Reciclagem do Lodo de Esgoto}

As técnicas para o processamento do lodo dependem do tipo, capacidade, localização da estação de tratamento, operações unitárias empregadas e o método para disposição final dos sólidos. O sistema selecionado deve ser capaz de receber o lodo produ- 
zido convertendo-o num produto ecologicamente $e$ economicamente aceitável para disposição.

Existem várias alternativas de destinação final como: os aterros sanitários, a incineração, a disposição no solo, recuperação de áreas degradadas, a reciclagem industrial $e$ a reciclagem agrícola. Esta última tem se destacado, a nível mundial, do ponto de vista técnico, econômico e ambiental, por viabilizar a reciclagem de nutrientes, promover melhorias físicas, especialmente na estruturação do solo e por apresentar uma solução definitiva para a disposição do lodo (ANDREOLI; PEGORINI, 1998).

O Quadro 1 apresenta as principais alternativas de disposição e de reciclagem do lodo de esgoto encontradas na literatura.

\begin{tabular}{|c|c|}
\hline $\begin{array}{c}\text { Alternativa de } \\
\text { Disposição }\end{array}$ & Referencial Teórico \\
\hline Aterro Sanitário & $\begin{array}{l}\text { (A. D. Santos, 2003); } \\
\text { (Andreoli, Sperling, \& Fernandes, 2001); } \\
\text { (Zaha \& Dumitrescu, 2008). }\end{array}$ \\
\hline Incineração & $\begin{array}{l}\text { (A. D. Santos, 2003); } \\
\text { (Andreoli et al., 2001); } \\
\text { (Zaha \& Dumitrescu, 2008). }\end{array}$ \\
\hline $\begin{array}{l}\text { Disposição } \\
\text { superficial no solo } \\
\text { (landfarming) }\end{array}$ & $\begin{array}{l}\text { (A. D. Santos, 2003); } \\
\text { (Andreoli et al., 2001); } \\
\text { (Zaha \& Dumitrescu, 2008). }\end{array}$ \\
\hline $\begin{array}{l}\text { Recuperação de } \\
\text { áreas degradadas }\end{array}$ & $\begin{array}{l}\text { (A. D. Santos, 2003); } \\
\text { (Andreoli et al., 2001); } \\
\text { (Zaha \& Dumitrescu, 2008). }\end{array}$ \\
\hline $\begin{array}{l}\text { Reciclagem } \\
\text { agrícola }\end{array}$ & $\begin{array}{l}\text { (A. D. Santos, 2003); } \\
\text { (Andreoli et al., 2001); } \\
\text { (Costa \& Costa, 2011); } \\
\text { (Cukjati, Zupancic, et al., 2012); } \\
\text { (Tsutiya, Comparini, Sobrinho, } \\
\text { \& Hespanhol, 2001); } \\
\text { (Zaha, Sauciuc, et al., 2011); } \\
\text { (Zaha \& Dumitrescu, 2008). }\end{array}$ \\
\hline $\begin{array}{l}\text { Reciclagem } \\
\text { Industrial }\end{array}$ & $\begin{array}{l}\text { (Araújo et al., 2005); } \\
\text { (Zaha \& Dumitrescu, 2008); } \\
\text { (Echevenguá \& Regina, 2012); } \\
\text { (Casagrande et al., 2008); } \\
\text { (Araújo et al., 2005); } \\
\text { (Devant, Cusidó \& Soriano, 2011) } \\
\text { (Valles et al., 2011); } \\
\text { (Cusidó \& Cremades, 2012); } \\
\text { (Liew et al., 2004); } \\
\text { (Lopes, Messias, Santos, Lima, } \\
\text { \& Menezes, 2009) } \\
\text { (Tian, Zuo, \& Chen, 2011); } \\
\text { (Martínez-García, Eliche-Quesada, } \\
\text { Pérez-Villarejo, Iglesias-Godino, } \\
\text { \& Corpas-Iglesias, 2012). }\end{array}$ \\
\hline
\end{tabular}

Quadro 1: Principais alternativas de disposição e reciclagem do lodo de esgoto

Fonte: Elaborado pelos autores deste artigo
O Quadro 2 descreve as vantagens e as desvantagens das alternativas de disposição e de reciclagem do lodo de esgoto listadas anteriormente.

\begin{tabular}{|c|c|c|}
\hline Alternativas & VANTAGENS & DESVANTAGENS \\
\hline Aterro Sanitário & $\begin{array}{l}\text { Baixo custo; } \\
\text { acelera } \\
\text { processo de } \\
\text { biodegradação. }\end{array}$ & $\begin{array}{l}\text { Necessita de grande } \\
\text { área, desperdício da } \\
\text { matéria orgânica; } \\
\text { distante de centro } \\
\text { urbano; solo deve } \\
\text { ser impermeável; } \\
\text { produção de gases e } \\
\text { lixiviado; dificuldade } \\
\text { de recuperação da } \\
\text { área pós-encerramento } \\
\text { do aterro. }\end{array}$ \\
\hline Incineração & $\begin{array}{l}\text { Redução drástica } \\
\text { de volume; } \\
\text { esterilização. }\end{array}$ & $\begin{array}{l}\text { Alto custo; } \\
\text { gerenciamento das } \\
\text { cinzas; poluição } \\
\text { atmosférica; destruição } \\
\text { da matéria orgânica. }\end{array}$ \\
\hline $\begin{array}{l}\text { Disposição } \\
\text { superficial no solo } \\
\text { (landfarming) }\end{array}$ & $\begin{array}{l}\text { Baixo custo; } \\
\text { disposição de } \\
\text { grandes volumes } \\
\text { por unidade } \\
\text { de área. }\end{array}$ & $\begin{array}{l}\text { Possível acumulação } \\
\text { de metais pesados e/ } \\
\text { ou elementos de difícil } \\
\text { decomposição no solo; } \\
\text { possível contaminação } \\
\text { do lençol freático; odor } \\
\text { indesejado; atração de } \\
\text { vetores; dificuldade de } \\
\text { reintegração da área. }\end{array}$ \\
\hline $\begin{array}{l}\text { Recuperação de } \\
\text { áreas degradadas }\end{array}$ & $\begin{array}{l}\text { Alta taxa de } \\
\text { aplicabilidade do } \\
\text { lodo; resultados } \\
\text { positivos sobre } \\
\text { a reconstituição } \\
\text { do solo e flora. }\end{array}$ & $\begin{array}{l}\text { Liberação de maus } \\
\text { odores; limitação de } \\
\text { composição do lodo } \\
\text { para tal uso; possível } \\
\text { contaminação da biota } \\
\text { e do lençol freático. }\end{array}$ \\
\hline $\begin{array}{l}\text { Reciclagem } \\
\text { agrícola }\end{array}$ & $\begin{array}{l}\text { Grande } \\
\text { disponibilidade } \\
\text { de áreas; efeitos } \\
\text { positivos sobre } \\
\text { solo; solução } \\
\text { em longo prazo; } \\
\text { potencial como } \\
\text { fertilizante; } \\
\text { resposta positiva } \\
\text { das culturas em } \\
\text { que é utilizado. }\end{array}$ & $\begin{array}{l}\text { Limitações referentes } \\
\text { a composição do lodo } \\
\text { e taxa de aplicação; } \\
\text { contaminação do solo; } \\
\text { contaminação dos } \\
\text { alimentos; possível } \\
\text { patogenicidade; } \\
\text { liberação de odores } \\
\text { indesejados. }\end{array}$ \\
\hline $\begin{array}{l}\text { Reciclagem } \\
\text { Industrial }\end{array}$ & $\begin{array}{l}\text { Destino } \\
\text { ambientalmente } \\
\text { seguro, } \\
\text { preservação } \\
\text { das jazidas. }\end{array}$ & Alteração nos processos. \\
\hline
\end{tabular}

Quadro 2: Vantagens e desvantagens das alternativas de disposição e reciclagem do lodo de esgoto encontradas na literatura

Fonte: Elaborado pelos autores deste artigo 


\subsection{Informações da Base de Dados sobre Patenteamento}

Foram realizadas pesquisas na base de patentes da EPO, utilizando a ferramenta Patent2Net para a extração dos dados.

A pesquisa foi executada seguindo os critérios descritos na Tabela 1 . Na consulta 1 buscou-se levantar o universo de patentes que contém as palavras-chaves: "sewage sludge", "recy*" e "utiliz*".

A quantidade expressiva do código IPC $\mathrm{C} 02 \mathrm{~F}$ (Tratamento de água, de águas residuais, de esgotos ou de lamas e lodos), na consulta 1 , já era esperado. Como o objetivo da pesquisa é valorizar o lodo de esgoto como matéria-prima buscou-se avaliar outro Cluster. Portanto, na consulta 2 foi introduzido o código IPC "C04B" (cimento; concreto; pedra artificial; cerâmica; refratários) com a finalidade de buscar grupo de patentes nesta área industrial.

Tabela 1: Critérios de pesquisa na base de dados e quantidade de patentes recuperadas

\begin{tabular}{ccc} 
Ordem & Consulta & $\begin{array}{c}\text { Quantidade DE } \\
\text { Patentes }\end{array}$ \\
\hline 1 & $\begin{array}{c}\text { ta }=\text { "sewage sludge" and } \\
(\mathrm{ta}=\text { recy* or ta }=\text { utiliz*) }\end{array}$ & 775 \\
$\mathrm{ta}=$ "sewage sludge" \\
and (ta $=$ recy* or ta $=$ \\
utiliz*) and ic $=$ C04B
\end{tabular}

Fonte: Elaborada pelos autores deste artigo

\subsubsection{Resultados da Pesquisa com Reciclagem de Lodo de Esgoto}

Os 775 depósitos de patentes encontradas na pesquisa foram agrupadas conforme as subclasses de classificação IPC, deste modo, possibilita visualizar as tecnologias utilizadas $e$ as tendências de reciclagem do lodo de esgoto.

O Quadro 3 e o Gráfico 1 apresentam as classificações recuperadas dos depósitos classificadas até a subclasse da classificação IPC. As classificações apresentadas são dos códigos com no mínimo cinco citações.

Pode-se observar que a maior parte dos depósitos de patentes está na Seção C (Química; Metalurgia) - $72 \%$ dos depósitos. A quantidade de depósitos de patentes no código C02F (196), que representa aproximadamente $26 \%$, já era esperado, por se tratar de tratamento de esgoto. É seguido pela classificação C04B com 116 depósitos de patentes (15,1\%) e C05F (70 patentes ou $9,1 \%$ ).

A Seção F (Engenharia Mecânica; Iluminação; Aquecimento; Armas; Explosão) - 16\% dos depósitos chamou a atenção pela segunda colocação. O código F23G com 46 patentes (6\%) que representam tecnologias em incineração e o código F26B com 41 patentes $(5,4 \%)$ que representam tecnologias de desidratação.

Outro ponto que vale ressaltar é a grande pulverização de outros códigos de classificação (66) utilizados. Melo Maricato et al. (2010) classifica esse grupo como em fase de maturidade ou que requerem investimento em desenvolvimento e pesquisa.

\begin{tabular}{|c|c|c|c|c|c|c|}
\hline IPC & SEÇÃo & SuBSEÇÃo & Classe & SubClasse & TOtAL & $\%$ \\
\hline A01G & $\begin{array}{l}\text { A - Necessidades } \\
\text { Humanas }\end{array}$ & Agricultura & $\begin{array}{l}\text { Agricultura; silvicultura; } \\
\text { pecuária; caça; captura } \\
\text { em armadilhas; pesca. }\end{array}$ & $\begin{array}{l}\text { Horticultura; cultivo de vegetais, } \\
\text { flores, arroz, frutas, vinhas, lúpulos } \\
\text { ou algas; silvicultura; irrigação. }\end{array}$ & 7 & $0,9 \%$ \\
\hline B01D & \multirow{2}{*}{$\begin{array}{l}\text { B - Operações de } \\
\text { Processamento; } \\
\text { Transporte }\end{array}$} & \multirow{2}{*}{$\begin{array}{l}\text { Separação; } \\
\text { mistura }\end{array}$} & $\begin{array}{l}\text { Processos ou } \\
\text { aparelhos físicos ou } \\
\text { químicos em geral. }\end{array}$ & Separação & 7 & $0,9 \%$ \\
\hline B09B & & & $\begin{array}{l}\text { Eliminação de resíduos } \\
\text { sólidos; recuperação } \\
\text { de solo contaminado. }\end{array}$ & Eliminação de resíduo sólido & 18 & $2,3 \%$ \\
\hline
\end{tabular}




\begin{tabular}{|c|c|c|c|c|c|c|}
\hline IPC & SEÇÃo & SuBSEÇÃo & Classe & Subclasse & Total & $\%$ \\
\hline $\mathrm{C} 01 \mathrm{~B}$ & \multirow{10}{*}{$\begin{array}{l}\text { C-Química; } \\
\text { Metalurgia }\end{array}$} & \multirow{10}{*}{ Química } & Química inorgânica & $\begin{array}{l}\text { Elementos não metálicos; } \\
\text { seus compostos. }\end{array}$ & 6 & $0,8 \%$ \\
\hline $\mathrm{CO} 2 \mathrm{~F}$ & & & $\begin{array}{l}\text { Tratamento de água, } \\
\text { de águas residuais, } \\
\text { de esgotos ou de } \\
\text { lamas e lodos. }\end{array}$ & $\begin{array}{l}\text { Tratamento de água, de } \\
\text { águas residuais, de esgotos } \\
\text { ou de lamas e lodos. }\end{array}$ & 196 & $25,6 \%$ \\
\hline $\mathrm{C} 04 \mathrm{~B}$ & & & $\begin{array}{l}\text { Cimento; concreto; } \\
\text { pedra artificial; } \\
\text { cerâmica; refratários. }\end{array}$ & $\begin{array}{l}\text { Cal; magnésia; escória; cimentos; } \\
\text { suas composições, por exemplo: } \\
\text { argamassa, concreto ou materiais } \\
\text { de construções similares; pedra } \\
\text { artificial; cerâmica; refratários; } \\
\text { tratamento da pedra natural. }\end{array}$ & 116 & $15,1 \%$ \\
\hline $\mathrm{C} 05 \mathrm{~F}$ & & & \multirow[b]{2}{*}{$\begin{array}{l}\text { Fertilizantes; sua } \\
\text { fabricação. }\end{array}$} & $\begin{array}{l}\text { Fertilizantes orgânicos; } \\
\text { fertilizantes resultantes do } \\
\text { tratamento de lixo ou refugos. }\end{array}$ & 70 & $9,1 \%$ \\
\hline C05G & & & & $\begin{array}{l}\text { Misturas de fertilizantes } \\
\text { pertencendo individualmente } \\
\text { a diversas subclasses da classe } \\
\text { c05; misturas de um ou mais } \\
\text { fertilizantes com substâncias } \\
\text { que não possuem atividade } \\
\text { especificamente fertilizante. }\end{array}$ & 16 & $2,1 \%$ \\
\hline $\mathrm{C} 09 \mathrm{~K}$ & & & $\begin{array}{l}\text { Corantes; tintas; } \\
\text { polidores; resinas } \\
\text { naturais; adesivos; } \\
\text { composições não } \\
\text { abrangidos em outros } \\
\text { locais; aplicações de } \\
\text { materiais não abrangidos } \\
\text { em outros locais. }\end{array}$ & $\begin{array}{l}\text { Materiais para aplicações } \\
\text { diversas, não incluídas em outro } \\
\text { local; aplicações de materiais } \\
\text { não incluídos em outro local. }\end{array}$ & 30 & $3,9 \%$ \\
\hline $\mathrm{C} 10 \mathrm{~B}$ & & & \multirow{3}{*}{$\begin{array}{l}\text { Indústrias do petróleo, } \\
\text { do gás ou do coque; } \\
\text { gases técnicos } \\
\text { contendo monóxido de } \\
\text { carbono; combustíveis; } \\
\text { lubrificantes; turfa. }\end{array}$} & $\begin{array}{l}\text { Destilação destrutiva de } \\
\text { substâncias carbonáceas para } \\
\text { produção de gás, coque, alcatrão } \\
\text { ou substâncias similares. }\end{array}$ & 11 & $1,4 \%$ \\
\hline C10J & & & & $\begin{array}{l}\text { Produção de gases contendo } \\
\text { monóxido de carbono e } \\
\text { hidrogênio a partir de matérias } \\
\text { carbonáceas sólidas por processos } \\
\text { de oxidação parcial envolvendo } \\
\text { oxigênio ou vapor; carburação } \\
\text { do ar ou de outros gases. }\end{array}$ & 15 & $2,0 \%$ \\
\hline $\mathrm{C} 10 \mathrm{~L}$ & & & & $\begin{array}{l}\text { Combustíveis não incluídos } \\
\text { em outro local; gás natural; gás } \\
\text { natural de sintético obtido por } \\
\text { processos não abrangidos pelas } \\
\text { subclasses c10g ou c10k; gás } \\
\text { liquefeito de petróleo; uso de } \\
\text { aditivos em combustíveis ou ao } \\
\text { fogo; acendedores de fogo. }\end{array}$ & 43 & $5,6 \%$ \\
\hline $\mathrm{C} 12 \mathrm{~N}$ & & & $\begin{array}{l}\text { Bioquímica; cerveja; } \\
\text { álcool; vinho; vinagre; } \\
\text { microbiologia; } \\
\text { enzimologia; engenharia } \\
\text { genética ou de mutação. }\end{array}$ & $\begin{array}{l}\text { Micro-organismos ou enzimas; } \\
\text { suas composições; propagação, } \\
\text { conservação, ou manutenção } \\
\text { de micro-organismos; } \\
\text { engenharia genética ou de } \\
\text { mutações; meios de cultura. }\end{array}$ & 5 & $0,7 \%$ \\
\hline
\end{tabular}




\begin{tabular}{|c|c|c|c|c|c|c|}
\hline IPC & SEÇÃo & SubSEÇÃo & Classe & Subclasse & TotaL & $\%$ \\
\hline E01C & \multirow[t]{2}{*}{$\begin{array}{l}\text { E - Construções } \\
\text { Fixas }\end{array}$} & \multirow[t]{2}{*}{ Edificação } & $\begin{array}{l}\text { Construção de rodovias, } \\
\text { ferrovias ou de pontes. }\end{array}$ & $\begin{array}{l}\text { Construção de ou revestimento } \\
\text { para estradas, praças de esporte } \\
\text { ou similares; máquinas ou } \\
\text { ferramentas auxiliares para } \\
\text { construção e reparos. }\end{array}$ & 6 & $0,8 \%$ \\
\hline E02D & & & $\begin{array}{l}\text { Engenharia } \\
\text { hidráulica; fundações; } \\
\text { terraplenagem. }\end{array}$ & $\begin{array}{l}\text { Fundações; escavações; } \\
\text { aterros; estruturas subterrâneas } \\
\text { ou subaquáticas. }\end{array}$ & 6 & $0,8 \%$ \\
\hline F23G & \multirow{4}{*}{$\begin{array}{l}\text { F - Engenharia } \\
\text { Mecânica; } \\
\text { Iluminação; } \\
\text { Aquecimento; } \\
\text { Armas; Explosão }\end{array}$} & \multirow{4}{*}{$\begin{array}{l}\text { Iluminação; } \\
\text { aquecimento }\end{array}$} & \multirow{2}{*}{$\begin{array}{l}\text { Aparelhos de combustão; } \\
\text { processos de combustão. }\end{array}$} & $\begin{array}{l}\text { Fornos crematórios; incineração } \\
\text { de refugos ou combustiveis de } \\
\text { baixo teor por combustão. }\end{array}$ & 46 & $6,0 \%$ \\
\hline F23K & & & & $\begin{array}{l}\text { Alimentação de combustíveis } \\
\text { aos aparelhos de combustão. }\end{array}$ & 8 & $1,0 \%$ \\
\hline F26B & & & Secagem & $\begin{array}{l}\text { Secagem de materiais ou de objetos } \\
\text { sólidos extraindo-lhes o líquido. }\end{array}$ & 41 & $5,4 \%$ \\
\hline $\mathrm{F} 27 \mathrm{~B}$ & & & $\begin{array}{l}\text { Fornalhas; fornos; } \\
\text { estufas; retortas. }\end{array}$ & $\begin{array}{l}\text { Fornalhas, fornos, estufas } \\
\text { ou retortas em geral; } \\
\text { aparelhos de sinterização a } \\
\text { céu aberto ou similares. }\end{array}$ & 8 & $1,0 \%$ \\
\hline
\end{tabular}

Quadro 3: Subclasses de classificação IPC identificadas nas patentes com tecnologias relacionadas a reciclagem de lodo de esgoto Fonte: Elaborada pelos autores deste artigo por meio da Classificação Internacional de Patentes

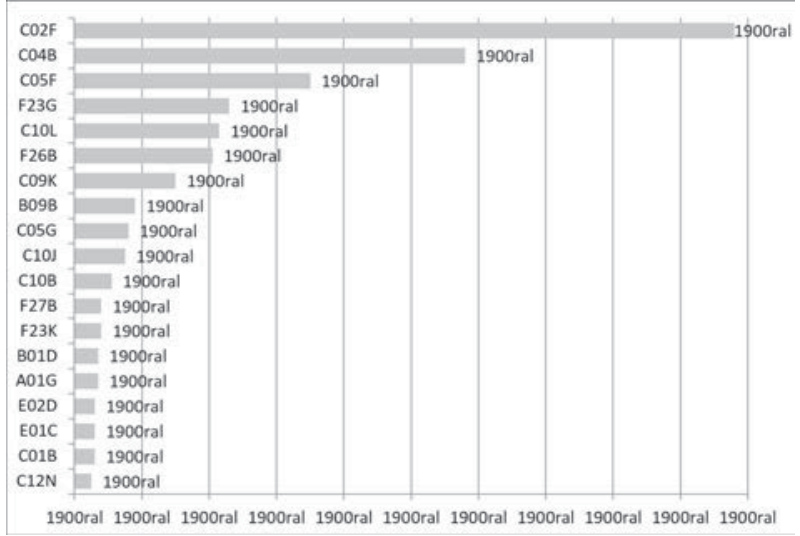

Gráfico 1: Ranking das classificações com maior quantidade de citações

Fonte: Adaptado de Patent2Net (2015)

O Gráfico 2 representa a evolução dos depósitos de patentes nos últimos 20 anos com os critérios de pesquisa. A análise do gráfico revela que em 2008 foi o ano com maior quantidade (46) de depósito. Até a data da pesquisa foram depositadas 15 patentes no ano 2015.

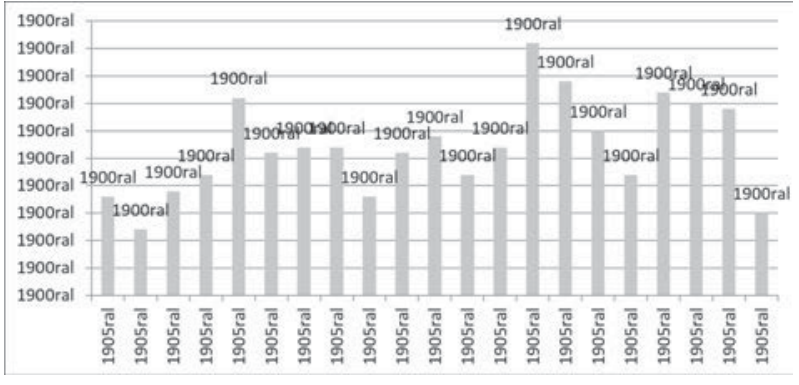

Gráfico 2: Evolução do depósitos de patentes sobre reciclagem de lodo nos últimos 20 anos Fonte: Adaptado de Patent2Net (2015)

O Gráfico 3 revela a predominância japonesa com 248 depósitos, $32 \%$ das de patentes depositadas, seguido pela China 121 (16\%) patentes e Estados Unidos 101 (13\%) depósitos.

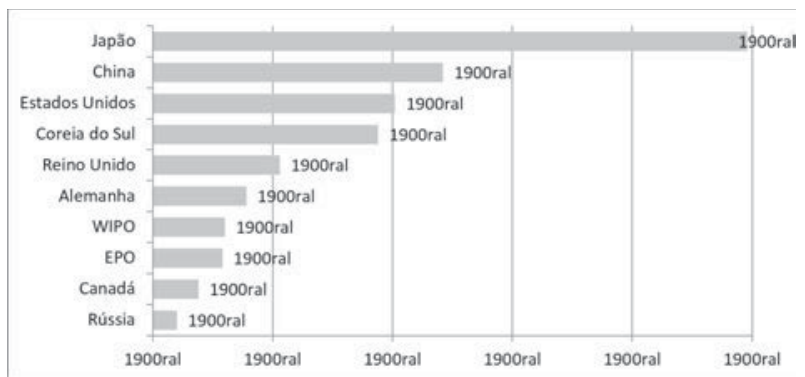

Gráfico 3: Quantidade de patentes sobre reciclagem de lodo recuperadas por país na base de dados

Fonte: Adaptado de Patent2Net (2015) 
No Gráfico 4 são apresentados os sete principais inventores e quatro grupos de inventores com 4, 3, 2 e 1 depósitos de patentes. No Gráfico 4 também é possível notar que um grande grupo de inventores (1.029) depositou somente uma patente. A liderança é dos americanos Gray Dahms (14) e John Glorioso (9).

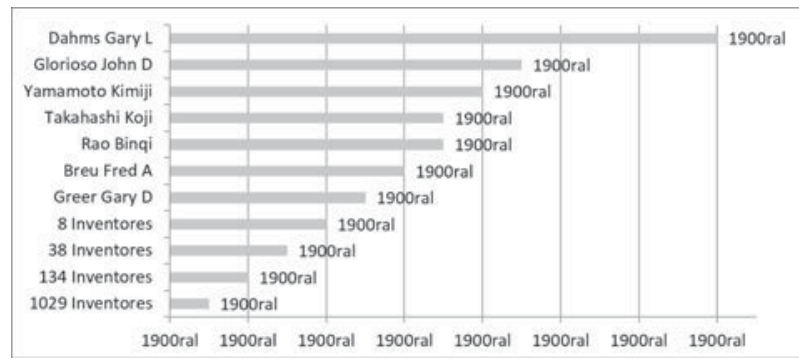

Gráfico 4: Distribuição dos depósitos por principais inventores na base de dados

Fonte: Adaptado de Patent2Net (2015)

O Gráfico 5 apresenta os principais requisitantes. As instituições japonesas destacam-se nas primeiras posições. O estudo também destaca liderança das empresas fabricante de cimento como um setor atuante no reaproveitamento de lodo de esgoto.

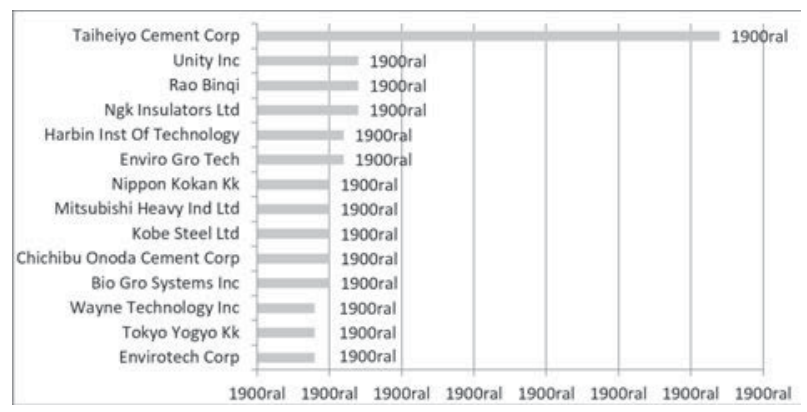

Gráfico 5: Principais requisitantes de patentes sobre reciclagem de lodo recuperadas

Fonte: Adaptado de Patent2Net (2015)

\subsection{Resultados da Pesquisa com Reciclagem de Lodo de Esgoto e Código IPC C04B}

Os 151 depósitos de patentes encontradas na pesquisa foram agrupadas conforme o grupo de classificação IPC, desse modo, possibilitou visualizar as tecnologias utilizadas $e$ as tendências de reciclagem do lodo de esgoto.
Observa-se no Quadro 4 que a maior parte dos depósitos de patentes estão nos Grupos C04B18 e C04B28 com 20,4\% depósitos cada. Os grupos são seguidos pelos Grupos C04B7 (11\%) e C04B33 (9,7\%).

\begin{tabular}{|c|c|c|c|}
\hline IPC & GRUPO & Total & $\%$ \\
\hline C04B7 & Cimentos hidráulicos & 22 & $11,2 \%$ \\
\hline C04B11 & Cimentos de sulfato de cálcio & 15 & $7,7 \%$ \\
\hline C04B14 & $\begin{array}{l}\text { Uso de materiais inorgânicos } \\
\text { como enchimento, por } \\
\text { exemplo, pigmentos para } \\
\text { argamassas, concreto ou } \\
\text { pedra artificial; tratamento } \\
\text { de materiais inorgânicos } \\
\text { especialmente adaptados para } \\
\text { melhorar suas propriedades de } \\
\text { enchimento em argamassas, } \\
\text { concreto ou pedra artificial. }\end{array}$ & 13 & $6,6 \%$ \\
\hline C04B18 & $\begin{array}{l}\text { Uso de aglomerados ou } \\
\text { materiais de rejeito ou refugo, } \\
\text { como enchimento para } \\
\text { argamassas, concreto ou } \\
\text { pedra artificial; tratamento de } \\
\text { aglomerados ou materiais de } \\
\text { rejeito ou refugo, especialmente } \\
\text { adaptados para melhorar } \\
\text { suas propriedades de } \\
\text { enchimento em argamassa, } \\
\text { concreto ou pedra artificial. }\end{array}$ & 40 & $20,4 \%$ \\
\hline C04B20 & $\begin{array}{l}\text { Uso de materiais como } \\
\text { enchimento, para argamassas, } \\
\text { concreto, pedra artificial ou } \\
\text { similar, de acordo com mais de } \\
\text { um dos grupos C04B 14/00- } \\
\text { C04B 18/00 e caracterizado } \\
\text { pela forma ou distribuição } \\
\text { granular; tratamento de } \\
\text { materiais de acordo com mais } \\
\text { de um dos grupos C04B 14/00- } \\
\text { C04B 18/00 especialmente } \\
\text { adaptados para melhorar suas } \\
\text { propriedades de enchimento } \\
\text { em argamassas, concreto } \\
\text { ou pedra artificial; Materiais } \\
\text { expandidos ou desfibrados. }\end{array}$ & 3 & $1,5 \%$ \\
\hline C04B24 & $\begin{array}{l}\text { Uso de materiais orgânicos } \\
\text { como ingredientes ativos } \\
\text { para argamassas, concreto, } \\
\text { pedra artificial ou similar, } \\
\text { por exemplo, plastificantes. }\end{array}$ & 3 & $1,5 \%$ \\
\hline C04B26 & $\begin{array}{l}\text { Composições de argamassa, } \\
\text { concreto ou pedra artificial, } \\
\text { contendo somente } \\
\text { ligantes orgânicos. }\end{array}$ & 2 & $1,0 \%$ \\
\hline
\end{tabular}




\begin{tabular}{|c|c|c|c|}
\hline IPC & GRUPO & Total & $\%$ \\
\hline C04B28 & $\begin{array}{l}\text { Composições de argamassas, } \\
\text { concreto, pedra artificial ou } \\
\text { similares, contendo ligantes } \\
\text { inorgânicos ou produtos } \\
\text { de reação de um ligante } \\
\text { inorgânico e um ligante } \\
\text { orgânico, por exemplo, } \\
\text { cimentos de policarboxilatos. }\end{array}$ & 40 & $20,4 \%$ \\
\hline C04B30 & $\begin{array}{l}\text { Composições de pedra } \\
\text { artificial ou similares, não } \\
\text { contendo ligantes. }\end{array}$ & 1 & $0,5 \%$ \\
\hline C04B32 & $\begin{array}{l}\text { Pedra artificial não prevista } \\
\text { por qualquer um dos } \\
\text { grupos desta subclasse. }\end{array}$ & 3 & $1,5 \%$ \\
\hline C04B33 & Artigos de argila. & 19 & $9,7 \%$ \\
\hline C04B35 & $\begin{array}{l}\text { Produtos modelados de } \\
\text { cerâmica caracterizados por } \\
\text { sua composição; Composições } \\
\text { de cerâmica; Processamento de } \\
\text { pós de compostos inorgânicos, } \\
\text { preparatório para manufatura } \\
\text { de produtos cerâmicos. }\end{array}$ & 15 & $7,7 \%$ \\
\hline C04B38 & $\begin{array}{l}\text { Argamassa porosa, } \\
\text { concreto, pedra artificial } \\
\text { ou artigos cerâmicos; } \\
\text { Preparação dos produtos. }\end{array}$ & 16 & $8,2 \%$ \\
\hline C04B40 & $\begin{array}{l}\text { Processos, em geral, para } \\
\text { influenciar ou modificar as } \\
\text { propriedades de composições } \\
\text { de argamassas, concreto } \\
\text { ou pedras artificiais, por } \\
\text { exemplo, sua capacidade } \\
\text { de decantação ou cura. }\end{array}$ & 3 & $1,5 \%$ \\
\hline C04B41 & $\begin{array}{l}\text { Pós-tratamento de argamassa, } \\
\text { concreto, pedra artificial } \\
\text { ou cerâmica; tratamento } \\
\text { de pedra natural. }\end{array}$ & 1 & $0,5 \%$ \\
\hline
\end{tabular}

Quadro 4: Grupo IPC identificadas nas patentes com tecnologias relacionadas à reciclagem de lodo de esgoto $e$ Código C04B

Fonte: Elaborada pelos autores deste artigo por meio da Classificação Internacional de Patentes

O Gráfico 6 revela a predominância japonesa com 96 depósitos, 63,3\% das de patentes depositadas, seguido pela China 19 patentes e Coreia do Sul 18 depósitos.

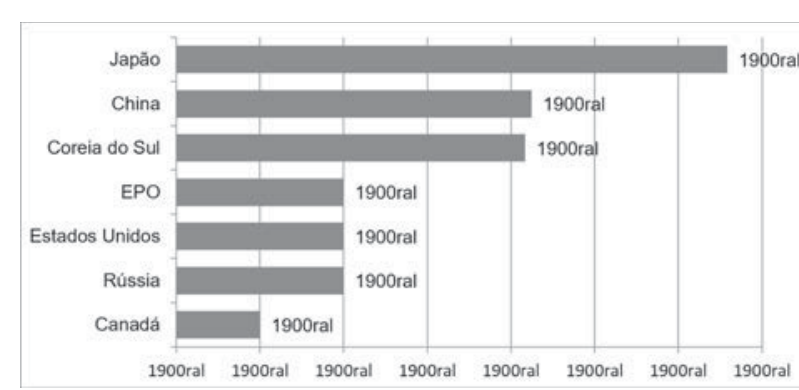

Gráfico 6: Quantidade de patentes sobre reciclagem de lodo recuperadas por país na base de dados Fonte: Adaptado de Patent2Net (2015)

O Gráfico 7 representa a evolução dos depósitos de patentes nos últimos 20 anos. A análise do gráfico revela que em 1999 foi o ano com maior quantidade (22) de depósito. Em 2014 foram depositadas quatro patentes.

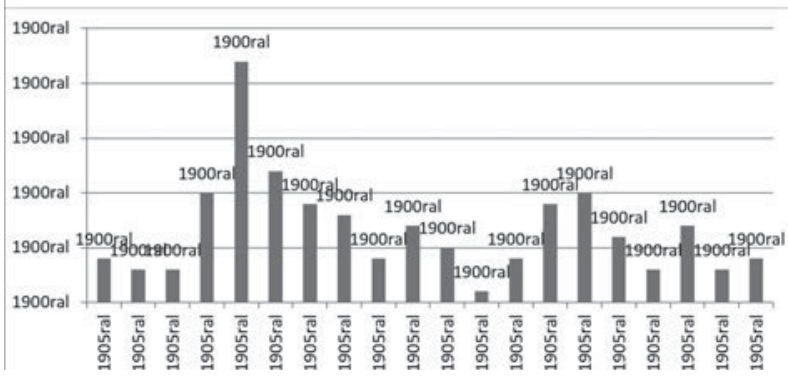

Gráfico 7: Evolução dos depósitos de patentes sobre reciclagem de lodo nos últimos 20 anos

Fonte: Adaptado de Patent2Net (2015)

No Gráfico 8 são apresentados os principais inventores. Os inventores japoneses destacam-se nas primeiras posições. O estudo também destaca uma grande quantidade de inventores com um ou dois pedidos de patentes.

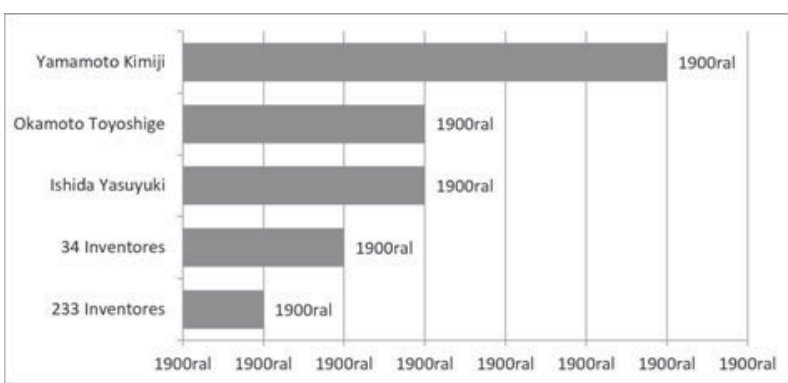

Gráfico 8: Distribuição dos depósitos por principais inventores

Fonte: Adaptado de Patent2Net (2015) 
Nas Figuras 1 e 2 podemos observar a análise da rede dos principais inventores. Na Figura 1 é apresentada a rede do maior inventor, na análise da rede fica constatado que apesar de ter uma quantidade expressiva de patente o inventor possui uma rede com baixa colaboração. A Figura 2 é demonstrada uma rede com maior colaboração $e$ interligação das redes dos inventores Okamoto Yoyoshige e Ishida Yasuyuki.

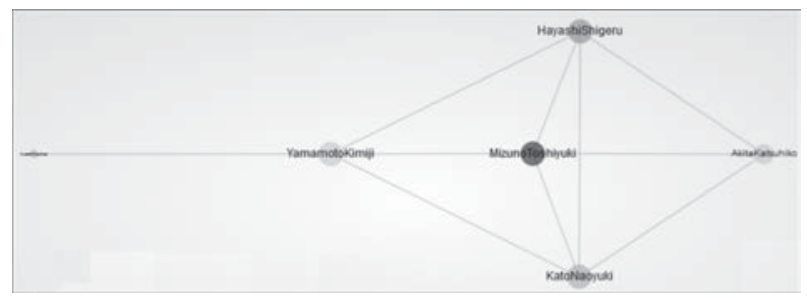

Figura 1: Análise da rede de colaboração do principal Inventor

Fonte: Adaptado de Patent2Net (2015)

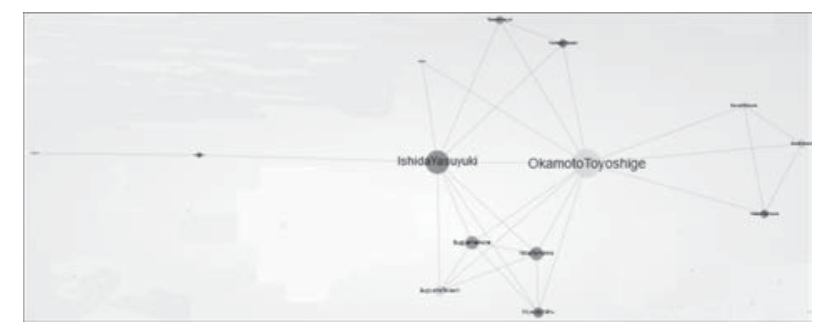

Figura 2: Análise da rede de colaboração dos inventores Okamoto Yoyoshige e Ishida Yasuyukir

Fonte: Adaptado de Patent2Net (2015)

O Gráfico 9 apresenta os principais requisitantes. Novamente as instituições japonesas destacam-se nas primeiras posições. O estudo também destaca liderança das empresas fabricante de cimento como um setor atuante no reaproveitamento de lodo de esgoto.

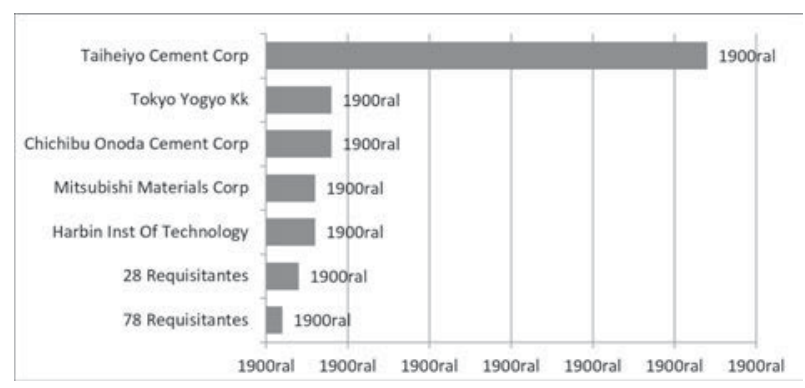

Gráfico 9: Principais requisitantes de patentes sobre reciclagem de lodo recuperadas

Fonte: Adaptado de Patent2Net (2015)

\section{Conclusões}

A inovação tecnológica é uma condição importante para o sucesso do processo relacionado aos sistemas produtivos. No caso da inovação sustentável, ela deve atender às dimensões da sustentabilidade $e$ assim gerar resultados econômicos, sociais e ambientais. Para orientar as atividades de pesquisa e desenvolvimento na criação de novas tecnologias voltadas a inovação, a busca de informação em documentos de patentes é fundamental. Nesse sentido, o presente estudo objetivou levantar a tecnologia utilizada para a reciclagem do lodo, visando a reciclagem de lodo de esgoto, baseando-se nas patentes relacionadas à este assunto. Estudos revelam que $70 \%$ das informações tecnológicas contidas nestes documentos não estão disponíveis em qualquer outro tipo de fonte de informação (INSTITUTO NACIONAL DE PROPRIEDADE INDUSTRIAL, 2015). As tecnologias para reciclagem do lodo de esgoto são estudadas de maneira mais intensiva nos últimos 20 anos e estabilizando após os anos 2010. Algumas contribuições para levantamento do estado da arte e da estratégia para reciclagem do lodo de esgoto foram alcançadas neste estudo. Os resultados podem subsidiar estratégias de melhoria na tecnologia de reciclagem, reutilização e valorização do lodo de esgoto. Sugerem-se estudos complementares para um entendimento amplo e dinâmico sobre o tema estudado. Outro estudo relevante seria da produção científica sobre reciclagem de lodo de esgoto como matéria-prima para obtenção de novos materiais. A utilização das informações contidas nos bancos de dados de patentes se torna uma ferramenta competitiva tornando-se uma variável estratégica para empresas interessadas.

\section{REFERÊNCIAS}

\section{ASSOCIAÇÃO BRASILEIRA DE NORMAS TÉCNICAS} (ABNT). ABNT NBR 10004. ABNT - Associação Brasileira de Normas Técnicas. 2004. Disponível em: <http://www.aslaa.com.br/legislacoes/NBR\%20n\%20 10004-2004.pdf> . Acesso em: 15 nov. 2015.

AMBIENTE BRASIL. Lodo de esgoto. 2006. Disponível em: <http://ambientes.ambientebrasil.com.br/residuos/ artigos/lodo_de_esgoto.html >. Acesso em: 15 nov. 2015. 
ANDREOLI, C. V.; PEGORINI, E. S. (1998). Gestão de biossólidos: situação e perspectivas. In: SEMINÁRIO SOBRE GERENCIAMENTO DE BIOSSÓLIDOS DO MERCOSUL. v. 1, Curitiba, 1998. Anais... Curitiba: Companhia de Saneamento do Paraná/Associação Brasileira de Engenharia Sanitária e Ambiental, 1998. p. 11-18.

ANDREOLI, C. V.; SPERLING, M. V.; FERNANDES, F. Lodo de esgoto: tratamento e disposição final. Belo Horizonte: Departamento de Engenharia Sanitária e Ambiental, UFMG; Companhia de Saneamento do Paraná - SANEPAR Saneamento, 2001. v. 6

ARAÚJO, F. S. D. et al. Caracterização de matériasprimas para reuso de lodo de ete em produtos cerâmicos. In: CONGRESSO BRASILEIRO DE ENGENHARIA SANITÁRIA E AMBIENTAL, 23, ABES, 2005. Anais... Campo Grande, 2005. p. 1-7.

BARBIERE, J. C.; ÁLVARES, A. C. T. Estratégia de patenteamento e licenciamento de tecnologia: conceitos e estudo de caso. Revista Brasileira de Gestão de Negócios, [S.l.], v. 7, n. 17, p. 58-68, 2005.

BARBIERI, J. C. et al. Inovação e sustentabilidade: novos modelos e proposições. Revista de Administração de Empresas, São Paulo, v. 50, n. 2, p. 146-154, 2010.

BARROSO, Wanise B. G. et al. Elaboration d'une base de données de médicaments pour faciliter la prise de décisions. Dans: VSST-2004. Toulouse, France: Dousset Bernard, 2004.

BRASIL. Lei n. 12.305, de 2 de agosto de 2010. Política Nacional de Resíduos Sólidos. [2010]. Disponível em: < http://www.mma.gov.br/port/conama/legiabre. cfm?codlegi=636>. Acesso em: 15 nov. 2015.

CALAZANS, R. B. A lógica de um discurso: o empresário Schumpeteriano. Ensaios FEE, Porto Alegre, p. 640-667, 1992.

CARVALHO, A. C.; STOROPOLI, J. H.; QUONIAM, L. M. Prospecção de patentes para a solução sustentável de problema da indústria da construção: o espaçador de concreto. Revista Inovação, Projetos e Tecnologias, [S.I.], v. 2, n. 1, p. 115-127, 2014.
CASAGRANDE JR., E. F. Inovação tecnológica e sustentabilidade: possíveis ferramentas para uma necessária inferface. Revista Educação \& Tecnologia, [S.l.], v. 8, 2011. Disponível em: < http://revistas.utfpr. edu.br/pb/index.php/revedutec-ct/article/view/1136/733> . Acesso em: 15 nov. 2015.

CASAGRANDE, M. C. et al. Reaproveitamento de resíduos sólidos industriais: processamento e aplicações no setor cerâmico. Cerâmica Industrial, [S.I.], v. 13, n. 1/2, p. 34-42, 2008

CONSELHO Nacional do Meio Ambiente. Ministério do Meio Ambiente. Resolução n. 375, de 29 de agosto de 2006. [2006]. Disponível em: <http://www.mma.gov. br/port/conama/res/res06/res37506.pdf>. Acesso em: 15 nov. 2015.

COSTA, A. de F. S.; COSTA, A. N. Manual de uso agrícola e disposição do lodo de esgoto para o estado do Espírito Santo. Espírito Santo: Incaper, 2011.

DE MELO MARICATO, J. et al. A. Análise bibliométrica da produção tecnológica em biodiesel: contribuições para uma política em CT\&I. Perspectivas em Ciência da Informação, [S.l.], v. 15, n. 2, p. 89-107, 2010.

DOU, Henri. Information brevet 2.0, transfert de technologies, valorisation des ressources. In: QUONIAM, Dans L.; LUCIEN, A.; PAPY, F. (Org.). Intelligence Compétitive 2.0: traité des sciences et techniques de l'information. Paris, FR: Hermes-Lavoisier, 2010. p. 181199.

ECHEVENGUÁ, B. E.; REGINA, G. M. Utilização do lodo de estação de tratamento de efluentes como matéria prima para compósitos cerâmicos. In: XIV ENPOS. Apresentado em Encontro Pós-Graduação UFPEL, Pelotas, 2012. Anais..., Pelotas, 2012.

EMBRAPA. Uso agrícola do lodo de esgoto: aspectos legais. 2006. Disponível em: <http://www.agencia.cnptia. embrapa.br/recursos/Pires_lodoID-0L1Y8Wo2Vx.pdf $>$. Acesso em: 15 nov. 2015.

EPO. Home. 2015. Disponível em: < http://www.epo.org/ searching/free/espacenet.html >. Acesso em: 15 nov. 2015.

FREEMAN, C.; SOETE, E. L. A Economia da inovação industrial. Campinas: Unicamp, 2008. 
Delmar Hirata • Cláudia Terezinha Kniess • Tatiana Tucunduva Philippi Cortese • Luc Quoniam

FUJINO, A.; STAL, E. Gestão da propriedade intelectual na universidade pública brasileira: diretrizes para licenciamento e comercialização. Cadernos de PósGraduação, [S.l.], v. 3, n. 2, p. 57-73, 2004.

GIL, C. A. Métodos e técnicas de pesquisa social. 5. ed. São Paulo: Atlas, 1999.

\section{INSTITUTO BRASILEIRO DE GEOGRAFIA E} ESTATÍSTICA (IBGE). PINTEC - Pesquisa de Inovação Tecnológica. 2005. Disponível em: <http://www.ibge. gov.br/home/estatistica/economia/industria/pia/empresas/ defaultempresa2005.shtm > . Acesso em: 15 nov. 2015.

\section{INSTITUTO NACIONAL DE PROPRIEDADE}

INDUSTRIAL (INPI). Portal INPI. [2015]. Disponível em: <http://www.inpi.gov.br/portal/>. Acesso em: 15 nov. 2015.

LEE, E. S. H.; SANTOS, F. J. (2011). Caracterização do lodo proveniente de estação de tratamento de esgoto (ETE) e estudo sobre seu potencial energético. In: II CONGRESSO BRASILEIRO DE GESTÃO AMBIENTAL. UNOPAR, Londrina, 2011. Apresentado em II Congresso Brasileiro de Gestão Ambiental. Anais... Londrina: UNOPAR, 2011. p. 2-9. Disponível em: < http://www. ibeas.org.br/congresso/Trabalhos2011/X-001.pdf > . Acesso em: 15 nov. 2015.

LIEW, A. G. et al. Reusability of sewage sludge in clay bricks. Journal of Material Cycles and Waste Management, [S.l.], v. 6, n. 1, p. 41-47, 2004.

LOPES, M. A. J. B. M. et al. Influência do Lodo de Esgoto em Características Físico-químicas do Solo Cultivado com Rabanete. In: XI ENCONTRO NACIONAL E I ENCONTRO INTERNACIONAL SOBRE GESTÃO EMPRESARIAL E MEIO AMBIENTE. Fortaleza, 2009. Apresentado em ENGEMA. Anais..., Fortaleza, ENGEMA, 2009.

MARTÍNEZ-GARCÍA, C. Sludge valorization from wastewater treatment plant to its application on the ceramic industry. Journal of Environmental Management, [S.I.], v. 95, S343-S348, 2009.

MARTINS, G. A.; TEÓPHILO, C. R. Metodologia da investigação científica para ciências sociais aplicadas. 2. ed. São Paulo: Atlas, 2009.
MELO, A. A. de; CZARNOBAY, V. Prospecção tecnológica das energias renováveis no Brasil: panorama atual e perspectivas após Resolução Normativa 482 e Programa de Patentes Verdes. Cadernos de Prospecção, [S.I.], v. 6, n. 4, p. 553, 2014.

MIKI, M. K.; ANDRIGUETI, E. J.; ALEM SOBRINHO, P. Tratamento da fase sólida em estações de tratamento de esgotos. In: TSUTIYA, M. T. et al. (Org.). Biossólidos na agricultura. São Paulo: SABESP, 2001. p. 41-87.

ORGANISATION for Economic Co-operation and Development. Frascati manual 2002: proposed standard practice for surveys on research and experimental development. Paris, 2002.

\section{ORGANIZAÇÃO PARA COOPERAÇÃO E} DESENVOLVIMENTO ECONÔMICO (OECD). Manual de Oslo: diretrizes para a coleta e interpretação de dados sobre inovação. 3. ed. Brasília, DF: FINEP, 2005.

\section{PULHMAN, A. C. A.; MOREIRA, C. F. Noções gerais} sobre proteção de tecnologia e produtos: versão inventor. São Paulo: Instituto de pesquisas Tecnológicas, 2004.

QUONIAM, L.; KNIESS, C. T.; MAZZIERI, M. R. A patente como objeto de pesquisa em Ciências da Informação e Comunicação. Encontros Bibli, [S.l.], v. 19, p. 243-268, 2014.

SANTANA, M. F. S.; LIMA, A. K. V. O.; MOURÃO, M. Avaliação Prospectiva do Açaí: análise através dos pedidos de patentes e referências bibliográficas. GEINTEC-Gestão, Inovação e Tecnologias, [S.I.], v. 4, n. 1, p. 437-452, 2014.

\section{SANTOS, A. D. Estudo das possibilidades de} reciclagem dos resíduos de tratamento de esgoto da Região Metropolitana de São Paulo. 2003. 282. p. Dissertação (Mestrado) - Escola Politécnica - USP, São Paulo, 2003. Disponível em: <http://www.teses.usp.br/ teses/disponiveis/3/3146/tde-30012004-134621/pt-br. php>. Acesso em: 23 nov. 2015.

SANTOS, H. F; TSUTIYA, M. T. Aproveitamento e disposição de lodo de estações de tratamento. Revista Engenharia Sanitária e Ambiental, [S.l.], v. 2, n. 2, 1997. 
SERAFINI, M. R. et al. Avaliação de tecnologias em dessalinização de água a partir da análise dos pedidos de patentes. GEINTEC-Gestão, Inovação e Tecnologias, [S.l.], v. 2, n. 1, p. 42-51, 2012.

TIAN, Y.; ZUO, W.; CHEN, D. Crystallization evolution, microstructure and properties of sewage sludge-based glass-ceramics prepared by microwave heating. Journal of Hazardous Materials, [S.l.], v. 196, 370-379, 2011.

TIDD, J.; BESSANT, J.; PAVITT, K. Gestão da inovação. Porto Alegre: Bookman, 2008.

TSUTIYA, M. T. et al. Biossólidos na agricultura. São Paulo, SABESP, 2001.

UCHÔA, S. B. B.; SILVA, A. S. da; SILVA, P. B. B. da. Mapeamento das patentes de complexação de metais pesados por meio de substâncias húmicas em estação de tratamentos de águas. Cadernos de Prospecção, [S.l.], v. 7, n. 2, p. 178, 2014.

VALLES, M. G. et al. Materiales vitrocerámicos a partir de lodos procedentes de una estación de depuración de aguas residuales urbanas (en la Ciudad de El-

Sadat, Egipto). Boletín de la Sociedad Española de

Cerámica y Vidrio, [S.l.], v. 50, n. 5, p. 261-266, 2011.

WORLD INTELLECTUAL PROPERTY ORGANIZATION (WIPO). [2015]. Disponível em: <http://www.wipo.int/ portal/index.html.en>. Acesso em: 15 nov. 2015.

ZAHA, C.; DUMITRESCU, L. Sludge Recycling - Needs and Trends. Bulletin of the Transilvania University of Brasov. Series I: Engineering Sciences, [S.I.], v. 1, n. 50, p. 299-304, 2008. 